Bull. Mater. Sci., Vol. 39, No. 4, August 2016, pp. 1039-1046. (c) Indian Academy of Sciences.

\title{
Reversible papain immobilization onto poly(AAm-MMA)-based cryogels
}

\author{
MURAT UYGUN ${ }^{1, *}$, RUKIYY YAVAŞER ${ }^{2}$ and DENIZ AKTAŞ UYGUN ${ }^{2}$ \\ ${ }^{1}$ Koçarlı Vocational and Training School, Adnan Menderes University, Aydın 09010, Turkey \\ ${ }^{2}$ Chemistry Department, Adnan Menderes University, Aydın 09010, Turkey
}

MS received 2 November 2015; accepted 23 January 2016

\begin{abstract}
In the present work, new dye ligand affinity chromatographic support for papain adsorption was synthesized. For this purpose, poly(acrylamide-methyl methacrylate) [poly(AAm-MMA)] cryogels were synthesized by using the free radical cryopolymerization technique. These cryogels were then functionalized with Reactive Green 19 dye and were characterized with Fourier transform infrared, environmental scanning electron microscopy, macroporosity and energy-dispersive $\mathrm{X}$-ray spectrometer analyses. Incorporation of the dye molecule onto cryogel structure was clearly demonstrated by these characterization techniques and pore diameter of the cryogel was found to be around 30-40 $\mu \mathrm{m}$. Effects of medium $\mathrm{pH}$, initial papain concentration, medium temperature and ionic strength on the papain adsorption onto dye-attached cryogel were also investigated. Maximum papain adsorption was found to be $40.66 \mathrm{mg} \mathrm{g}^{-1}$ cryogel by using $\mathrm{pH} 5.5$ acetate buffer at $25^{\circ} \mathrm{C}$. Reusability profile of the cryogel was also investigated and it was found that the adsorption capacity of the cryogel decreased only about $2.13 \%$ at the end of the 10 reuses. Activity studies of papain in desorption medium were carried out and it was found that desorbed papain was active and showed $88.5 \%$ of its initial activity.
\end{abstract}

Keywords. Dye affinity; Reactive Green 19; cryogel; papain.

\section{Introduction}

Protease class enzymes catalyse the hydrolysis of proteins into peptides and amino acids [1]. Papain is a proteolytic enzyme, which is a carbohydrate free, basic and single chain protein with 212 amino acid residues [2]. The enzyme has three disulphide bonds and one sulphohydride group; and its active centre includes cysteine and histidine residues. Main source of this enzyme is Carica papaya latex and papain has been used for the treatment of large skin lesions due to its antiinflammatory, antibacterial and antioxidant behaviours $[3,4]$. Papain has been also used in the food industry, for example, meat tenderizing, protein hydrolysate production, juice and beer clarification, cheese production, and so on [5]. In recent times, papain has been used for the isolation of cells and separation of various biomolecules [6].

Papain has been purified from $C$. papaya latex traditionally by using precipitation methods [7-10]. At the end of this purification process, final enzyme preparation contains other proteases and contaminants. Therefore, various alternative purification strategies have been developed for purification of papain by using different chromatographic techniques such as ion exchange or affinity separation [11-13].

Affinity chromatography techniques use number of specific interactions by using special ligands such as, enzymes, coenzymes, cofactors, antibodies, amino acids, oligopeptides, proteins, nucleic acids and so on [14-20]. However, these ligands are very expensive due to their time consumption and difficult purification procedures. Also immobilization

\footnotetext{
*Author for correspondence (muratuygun@gmail.com)
}

of these ligands to the support material by protecting their activity is very difficult [21-24]. To eliminate these drawbacks, new and effective ligands have been synthesized and applied for the affinity separation techniques. Dye ligands are good alternatives for these ligands and have already been used for adsorption of various biomolecules. These dye ligands are also called as affinity ligands due to mimicking of the substrate and cofactor structure of some certain enzymes. These dye ligands can easily interact with active centre of enzymes [25]. Dye ligands are very cheap and commercially available, and they can also be immobilized easily to the various support materials. Reactive dyes, which are also used as a textile dye, have great potential for adsorption or purification of biomolecules. These reactive dyes generally have mono- or di-chlorotriazine ring and they can easily be immobilized to the support surface by using these reactive groups $[26,27]$. One of the intensively used triazine dyes is Reactive Green 19 and it has been highly preferred as an affinity ligand for protein separation and purification studies [28]. Reactive Green 19 is a diclorotriazine dye which contains six sulphonic acid groups and five amino groups [29,30]. These dye ligands can interact with proteins by electrostatic, hydrophobic and hydrogen bond, or complex interaction of these forces $[26,27]$. In the present work, Reactive Green 19 dye was used as an affinity ligand. This is a dichlorotriazine dye and contains six sulphonic acid groups, and a total of five primary and secondary amine groups $[29,31]$.

Gel bead-based conventional chromatographic techniques are still preferred for the separation or purification of biomolecules. However, they have some limitations such as reduced flow rate, high pressure drops, low productivity and difficulties 
in 'scale up' applications. Working with these bead-based columns requires pre-separation techniques because these matrices are not appropriate for crude extracts and viscous samples like whole blood. Sample preparation is not only the important process for chromatographic techniques, but also it is a time-consuming step. New polymeric materials have been synthesized and used as an alternative for the conventional bead-based chromatographic materials, to eliminate these drawbacks. These materials can be in the form of membrane, monolith or cryogel. Cryogels are polymeric, monolithic materials, characterized with their interconnected macroporous sponge-like structure. Cryogels show very high flow rates and low pressure drop due to their macroporous structure. They are also compatible with viscous materials without any blockage in their pores. Cryogels are very cheap materials, and they can be synthesized at subzero temperatures with any kind of polymerizable monomers [32]. Cryogels have been recently used for the applications in separation and adsorption of biomolecules, immobilization of biocatalysts, chromatography of cells and organelles and three-dimensional scaffold structures for cell culture studies [33].

In the present work, Reactive Green 19 attached poly(acrylamide-methyl methacrylate) [poly(AAm-MMA)] cryogels were synthesized and characterized with Fourier transform infrared, environmental scanning electron microscopy, macroporosity and energy-dispersive X-ray spectrometer analyses. Prepared dye affinity cryogels were used for the adsorption of papain from its aqueous solution. Effects of medium $\mathrm{pH}$, initial papain concentration, medium temperature and ionic strength to the adsorption capacity of the Reactive Green 19 attached poly(AAm-MMA) cryogels were investigated. Also, reusability profile of the cryogel was studied for 10 successive reuses by using the same cryogel.

\section{Materials and methods}

\subsection{Materials}

Papain (from C. papaya), acrylamide, methyl methacrylate, $N, N^{\prime}$-methylene bis(acrylamide) (MBAAm), ammonium persulphate (APS) and $N, N, N^{\prime}, N^{\prime}$-tetramethylene diamine (TEMED) were purchased from Sigma (Steinheim, Germany). All other chemicals were of analytical grade and used as supplied. Solutions used in this study were prepared by using deionized ultrapure Millipore Simplicity ${ }^{\circledR}$ water (18.2 $\mathrm{M} \Omega \mathrm{cm})$.

\subsection{Synthesis of poly(AAm-MMA) cryogel}

Poly(AAm-MMA) cryogels were synthesized by the free radical cryopolymerization technique. For this, AAm and MMA were used as monomers of the polymeric backbone, while APS and TEMED were chosen as an initiator and activator, respectively. A typical cryogel preparation procedure is described as follows: first, $1.07 \mathrm{ml}$ of MMA and $0.71 \mathrm{~g}$ of AAm were dissolved in $5.0 \mathrm{ml}$ of distilled water. This monomer solution was then mixed with $10.0 \mathrm{ml}$ of MBAAm solution $(0.285 \mathrm{~g})$ and cooled by using an ice bath. Immediately after the addition of $25 \mu \mathrm{l}$ TEMED and $20 \mathrm{mg}$ APS, polymerization solution was poured into a plastic syringe and incubated at $-12^{\circ} \mathrm{C}$ for $24 \mathrm{~h}$. At the end of the polymerization process, synthesized cryogels were thawed and washed thrice with $100 \mathrm{ml}$ of water, to remove the unreacted reagents.

\subsection{Reactive Green 19 immobilization onto poly(AAm-MMA) cryogel}

Reactive Green 19 dye was chosen as an affinity ligand for papain and was covalently immobilized to the poly(AAm-MMA) cryogel by nucleophilic substitution reaction. For this purpose, synthesized cryogels were subjected with $100 \mathrm{ml}$ of Reactive Green 19 dye solution $\left(5 \mathrm{mg} \mathrm{ml}^{-1}\right.$, in $5 \% \mathrm{NaOH}$ ) by passing through into the cryogel column by using a peristaltic pump at $80^{\circ} \mathrm{C}$ for $2 \mathrm{~h}$. By this way, a nucleophilic substitution reaction takes place between chloride of Reactive Green 19 and amino group of AAm monomer, with the elimination of $\mathrm{NaCl}$, which cause the coupling of Reactive Green 19 to the cryogel column under alkaline conditions. Any remaining chlorine atoms in the dye-attached cryogel column were converted to amino group by treating with $2 \mathrm{M}$ of $\mathrm{NH}_{4} \mathrm{Cl}$ at $\mathrm{pH} 8.5$ for $4 \mathrm{~h}$ at room temperature [34]. At the end of the dye immobilization process, dyed cryogels were rinsed thrice with 100 $\mathrm{ml}$ of water to wash the unbounded dye molecules and any remaining $\mathrm{NH}_{4} \mathrm{Cl}$ from the cryogel.

\subsection{Characterization of Reactive Green 19 immobilized poly(AAm-MMA) cryogel}

The overall structure, morphology and pore size of the cryogel were examined by ESEM. For this purpose, wet samples were mounted on an ESEM device (Philips XL-30S FEG, the Netherlands) and ESEM pictures of the cryogels were taken. Macroporosity of the synthesized cryogel was also determined. For this, cryogels were first swelled up to equilibrium and weighed ( $\left.m_{\text {swollen }}\right)$; then squeezed by hand and weighed ( $\left.m_{\text {squeezed }}\right)$; and finally dried until the constant weight $\left(m_{\text {dried }}\right)$ obtained. Macroporosity was calculated by the following equation:

$$
\text { Macroporosity } \%=\left[\frac{\left(m_{\text {swollen }}-m_{\text {squeezed }}\right)}{m_{\text {dried }}}\right] \times 100 .
$$

FTIR spectrum of the synthesized cryogels was also obtained by using a FTIR spectrophotometer (Varian FTS 7000, USA). For this, synthesized cryogels were dried in an oven at $60^{\circ} \mathrm{C}$ for 4 days and were grounded. Then, cryogel sample was mixed with IR grade $\mathrm{KBr}$ and pressed into a pellet form, and FTIR spectrum of the cryogel was read. EDX analysis of the cryogel was used for the evaluation of the incorporation of Reactive Green 19 dye onto the cryogel structure. 
For this, EDX spectrum of the cryogel was taken by using an EDX instrument (LEO EVO 40, Carl Zeiss NTS, USA) and incorporated amount of the dye was calculated from this data by using the sulphur stoichiometry. Namely, each Reactive Green 19 dye molecule has six sulphur atoms, and EDX results give total amount of sulphur atoms per gram of cryogel mass. By this way, total attached amount of dye molecule can be proportioned.

\subsection{Papain adsorption onto dye-immobilized cryogel}

Papain adsorption experiments were carried out by using a continuous column system. For a typical papain adsorption study, $5 \mathrm{ml}$ of papain solution was passed through the cryogel column for $2 \mathrm{~h}$ at room temperature. To search optimum papain adsorption conditions, some system parameters were changed. The most efficient parameter, which affects the adsorption is $\mathrm{pH}$. The effect of $\mathrm{pH}$ on the papain adsorption onto Reactive Green 19 immobilized poly(AAm-MMA) cryogel was investigated by using various buffer solutions (0.1 $\mathrm{M}$ of acetate buffer for $\mathrm{pH} 4.0-5.5 ; 0.1 \mathrm{M}$ of phosphate buffer for $\mathrm{pH}$ 6.0-7.0). Adsorption isotherm was investigated by using different papain concentrations. For this, initial papain concentrations were varied between 0.1 and $1.5 \mathrm{mg}$ $\mathrm{ml}^{-1}$. Effect of medium temperature on the papain adsorption was also investigated within the temperature range of 4-60 ${ }^{\circ} \mathrm{C}$. Medium ionic strength also affects the adsorbed amount of papain. Therefore, medium ionic strength of the papain adsorption medium was changed between 0 and $1 \mathrm{M}$ by using solid $\mathrm{NaCl}$.

Adsorbed amount of papain onto dye ligand cryogel columns was determined spectrophotometrically (Shimadzu UV 1601, Japan) at $280 \mathrm{~nm}$ by measuring the initial and final papain concentrations in the adsorption solution.

\subsection{Desorption of papain and reusability profile of the cryogel}

Desorption of papain from the cryogel is very important process to regenerate the cryogel for next adsorption steps. Adsorbed papain was desorbed from the cryogel by using $2 \mathrm{M}$ of $\mathrm{NaCl}$ (in $\mathrm{pH} 4$ acetate buffer). For this, $5 \mathrm{ml}$ of desorption solution was passed through the cryogel column for $1 \mathrm{~h}$ at room temperature. At the end of the desorption process, cryogel was washed with $50 \mathrm{ml}$ of water and equilibrated with appropriate buffer solution for next adsorption step. Reusability profile of the dye-immobilized cryogel was also investigated by using the same cryogel column. For this, papain adsorption/desorption process was repeated for 10 cycles and adsorption efficiency of the cryogel was estimated by the above-mentioned adsorption procedure.

\subsection{Papain activity study}

It is expected that desorbed enzyme preparation should be active and retain large part of its activity. For this important matter, papain activity measurements were carried out for desorption media by using the Homaei method [35]. In this method, casein was used as a substrate for papain activity and a casein solution was prepared by dissolving $1 \mathrm{~g}$ of casein in $100 \mathrm{ml}$ of phosphate buffer (50 mM, pH 7.5) containing $38 \mathrm{mM}$ EDTA and $34 \mathrm{mM}$ cysteine. For this activity method, $400 \mu \mathrm{l}$ of casein solution mixed with $400 \mu \mathrm{l}$ of papain solution (with different dilutions) and incubated for $10 \mathrm{~min}$ at room temperature. At the end of this incubation period, protein hydrolysis was terminated by trichloroacetic acid solution $(800 \mu \mathrm{l}, 10 \%)$. The mixture was incubated for $30 \mathrm{~min}$ more at room temperature and centrifuged at $12,000 \mathrm{~g}$ for $10 \mathrm{~min}$. Absorbance of the supernatant was measured spectrophotometrically at $280 \mathrm{~nm}$. One enzyme unit was determined as the amount of enzyme that hydrolyses the casein to produce equivalent absorbance to $1 \mu \mathrm{mol}$ of tyrosine per minute with tyrosine standard [36]. All protein concentrations were determined by using the Bradford method [37].

\section{Results and discussion}

\subsection{Characterization of dye-immobilized cryogel}

Cryogels have been recently preferred and used for the adsorption/purification of biomolecules due to their great macropores, easy to prepare properties and ready to scale up opportunities. In this study, poly(AAm-MMA) cryogels were synthesized by using the cryopolymerization technique. Prepared cryogels were opaque and had spongy structure. When compressed by hand, cryogels could lose all the water accumulated inside its pores. These squeezed cryogels could also return its original shape and size when submerged in water. These cryogel columns were then functionalized with Reactive Green 19 dye and were used for the affinity adsorption of papain. Preparation of the cryogel and its modification is schematically summarized in figure 1. ESEM picture of the Reactive Green 19 attached poly(AAm-MMA) cryogel is shown in figure 2. As seen here, synthesized cryogels were highly porous and their pore size was about 30-40 $\mu \mathrm{m}$. Their sponge like pattern and interconnected pore structure can also be seen clearly. Macroporosity of the synthesized cryogel was calculated as $68.72 \%$, and it can be concluded that prepared cryogels were highly porous and supported the ESEM findings. FTIR spectrum of the plain Reactive Green 19 and the Reactive Green 19 attached poly(AAm-MMA) cryogel are shown in figure $3 \mathrm{a}$ and $\mathrm{b}$, respectively. As demonstrated here, stretching bands of $-\mathrm{OH}$ and $\mathrm{NH}_{2}$ are located around $3500 \mathrm{~cm}^{-1}$. $-\mathrm{OH}$ comes from the dye molecule, while $\mathrm{NH}_{2}$ is from acrylamide monomer. Characteristic stretching band, $\mathrm{CH}_{3}$ is located around $2900 \mathrm{~cm}^{-1}$ and it is from methyl methacrylate monomer. Also carbonyl stretching band can be seen at around $1750 \mathrm{~cm}^{-1}$. This band is very sharp in the FTIR of the dye-attached cryogel and only comes from the acrylamide and methyl methacrylate monomers. Symmetric and asymmetric stretching bands of $\mathrm{S}=\mathrm{O}$ are located 


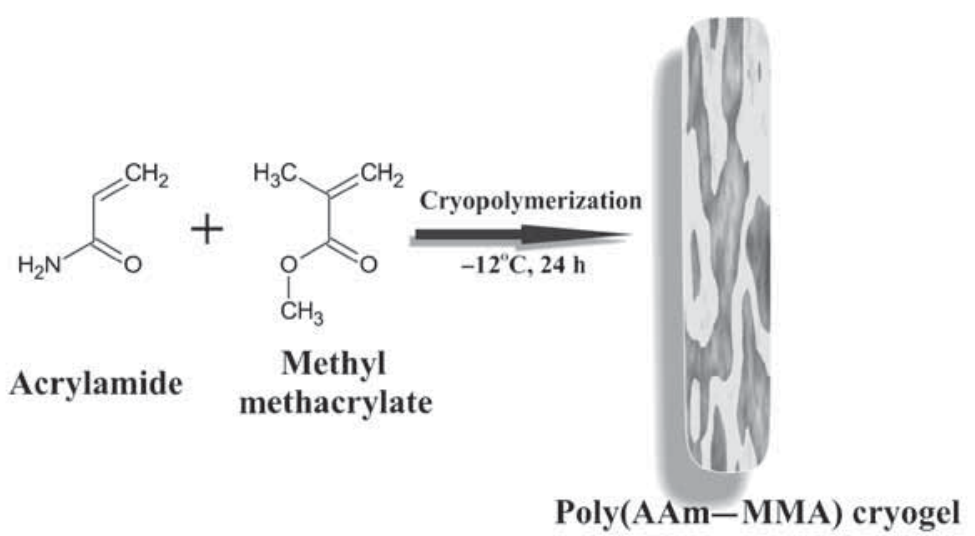

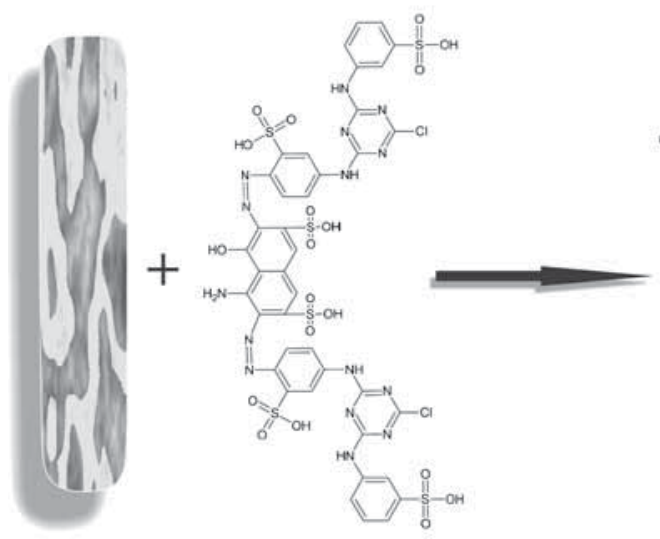

Reactive Green 19

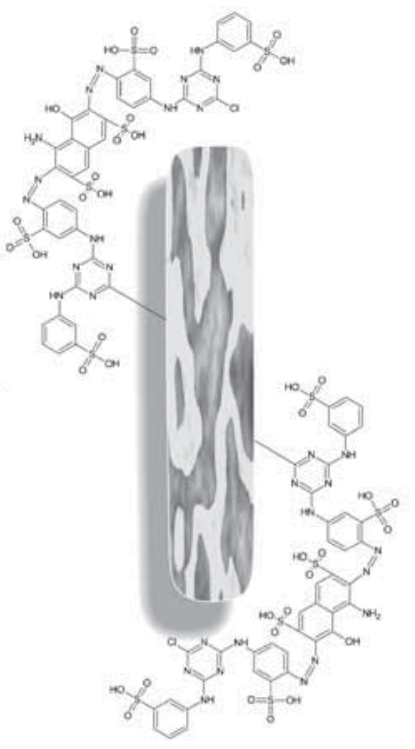

\section{Reactive Green 19 attached poly(AAm-MMA) cryogel}

Figure 1. Schematic presentation for the preparation of Reactive Green 19 attached poly(AAm-MMA) cryogel.

around 1100 and $1200 \mathrm{~cm}^{-1}$, respectively, as overlapping bands at dye-attached cryogel spectrum, while these bands are very apparent at the FTIR of plain dye molecule. Also sharp peak at around $1500 \mathrm{~cm}^{-1}$ is from aromatic groups of the dye molecule. This band is very visible at both FTIR bands of plain dye and dye-attached cryogel. These findings show that Reactive Green 19 dye was successfully attached to the cryogel backbone. EDX spectrum of the dye-attached cryogel is demonstrated in figure 4 . As clearly seen here, synthesized cryogels were composed of $\mathrm{C}, \mathrm{N}, \mathrm{O}$ and $\mathrm{S}$ atoms. Because $\mathrm{S}$ atoms are from the dye molecule, it can be concluded that Reactive Green 19 dye was successfully incorporated to the cryogel structure. By using EDX data, amount of the attached dye molecule onto cryogel structure was also calculated and found to be $12.50 \mu \mathrm{mol} \mathrm{g}^{-1}$ cryogel by using sulphur stoichiometry.

\subsection{Adsorption of papain onto the dye attached cryogel}

Dye-affinity techniques have been deeply used for the adsorption of proteins and biomolecules because of their cofactor like structures. Dye molecules are commercially available and very cheap, and can be easily immobilized onto various support materials. In this work, Reactive Green 19 dye was covalently attached onto poly(AAm-MMA) cryogel. Papain was adsorbed onto these dye-modified cryogels with continuous mode and adsorption conditions were optimized. $\mathrm{pH}$ is the most effective condition, which affects the adsorption of papain onto the support materials. Figure 5 shows the effect of medium $\mathrm{pH}$ on the papain adsorption capacity. As clearly seen here, maximum papain adsorption value was found to be $20.93 \mathrm{mg} \mathrm{g}^{-1}$ cryogel at pH 5.5 acetate buffer. Also, $\mathrm{pH}$ profile for the papain adsorption was very stable 
between the $\mathrm{pH}$ values of 4.5 and 6.5 and adsorbed amount of papain did not change significantly within this $\mathrm{pH}$ range. But when the medium $\mathrm{pH}$ was increased to 7.5 , adsorbed amount of papain decreased dramatically. Under these experimental conditions, papain molecule was cationic, while dyeattached cryogel tended to be anionic due to isoelectric point of papain is 8.75 and sulphonate groups of the Reactive Green 19 dye has $\mathrm{pKa}$ value around 0.8 [38]. By this observation, it can be concluded that interaction between the papain and dye-attached cryogel might be electrostatic. On the contrary, adsorbed amount of papain decreased significantly when $\mathrm{pH}$ increased to around 7. Papain adsorption process taken place by the interaction of dye molecules attached to the cryogel structure and surface amino acid residues of the papain molecule. This decrease in the adsorption value was probably

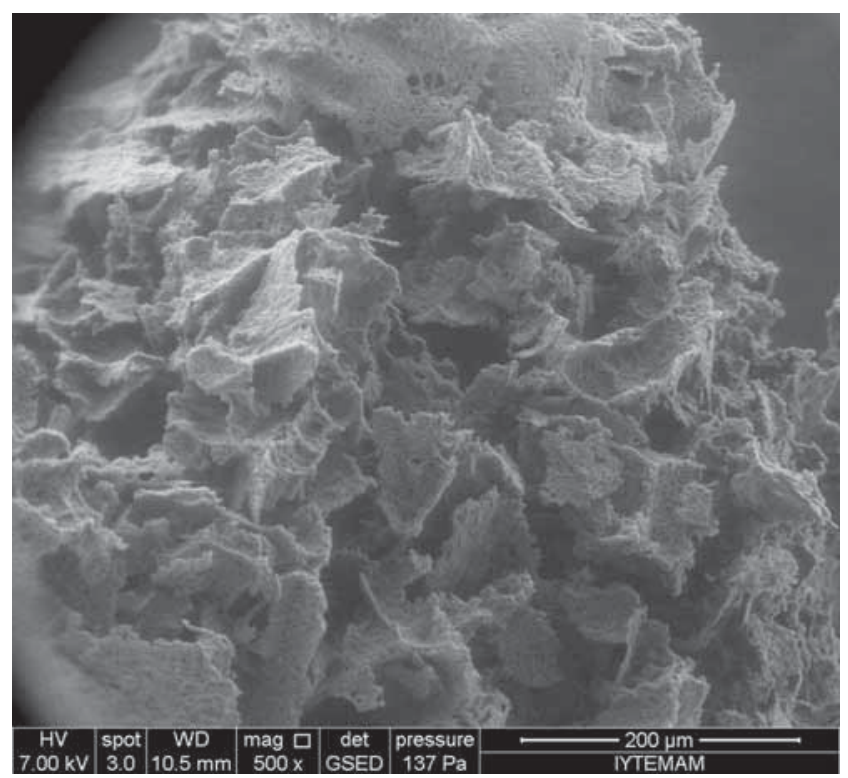

Figure 2. ESEM picture of the Reactive Green 19 attached poly (AAm-MMA) cryogel. due to the ionization of the surface amino acid residues of the papain molecule at higher $\mathrm{pH}$ values than $\mathrm{pH} 7$.

The effect of the initial papain concentration on the papain adsorption onto dye-attached cryogel structures was investigated by using the concentration range of $0.1-1.5 \mathrm{mg} \mathrm{ml}^{-1}$. Figure 6 shows the concentration isotherm for the papain adsorption. As clearly seen in this picture that adsorbed amount of papain increased linearly with the increase in the initial papain concentration. But when the initial papain concentration was further increased, adsorbed amount of papain did not significantly change and a saturation value was monitored at this point. This saturation profile generally occurs in the adsorption process. In this study, dye-affinity support reached its maximum adsorption capacity after the papain concentration of $1 \mathrm{mg} \mathrm{ml}^{-1}$ and could not adsorb any more papain from the adsorption solution.

To evaluate the adsorption process, two main isotherms were used: Langmuir and Freundlich isotherms are the most used and applied isotherms and expressed as following equations, respectively:

$$
\begin{aligned}
& 1 / q_{\mathrm{e}}=\left(1 / q_{\max }\right)+\left(1 / q_{\max } b\right)\left(1 / C_{\mathrm{e}}\right), \\
& \ln q_{\mathrm{e}}=1 / n\left(\ln C_{\mathrm{e}}\right)+\ln K_{\mathrm{f}} .
\end{aligned}
$$

Here adsorbed papain amount at equilibrium is $q_{\mathrm{e}}\left(\mathrm{mg} \mathrm{g}^{-1}\right)$; maximum papain adsorption capacity of the cryogel is $q_{\max }$ $\left(\mathrm{mg} \mathrm{g}^{-1}\right) ; C_{\mathrm{e}}$ the equilibrium papain concentration $(\mathrm{mg}$ $\mathrm{ml}^{-1}$ ); $b$ and $K_{\mathrm{f}}$ the Langmuir and Freundlich constants, respectively, and $n$ the Freundlich exponent. Kinetic constants of Langmuir and Freundlich isotherms are summarized in table 1. As clearly seen in this table that Langmuir model was appropriate for the adsorption of papain onto Reactive Green 19 attached poly(AAm-MMA) cryogel. With this finding, it can be concluded that the overall papain adsorption process was homogeneous and dye ligands covered the surface of the cryogel as a monolayer. Papain enzyme was bound equally to these available dye ligands and there was no interaction between the adsorbed species [39].

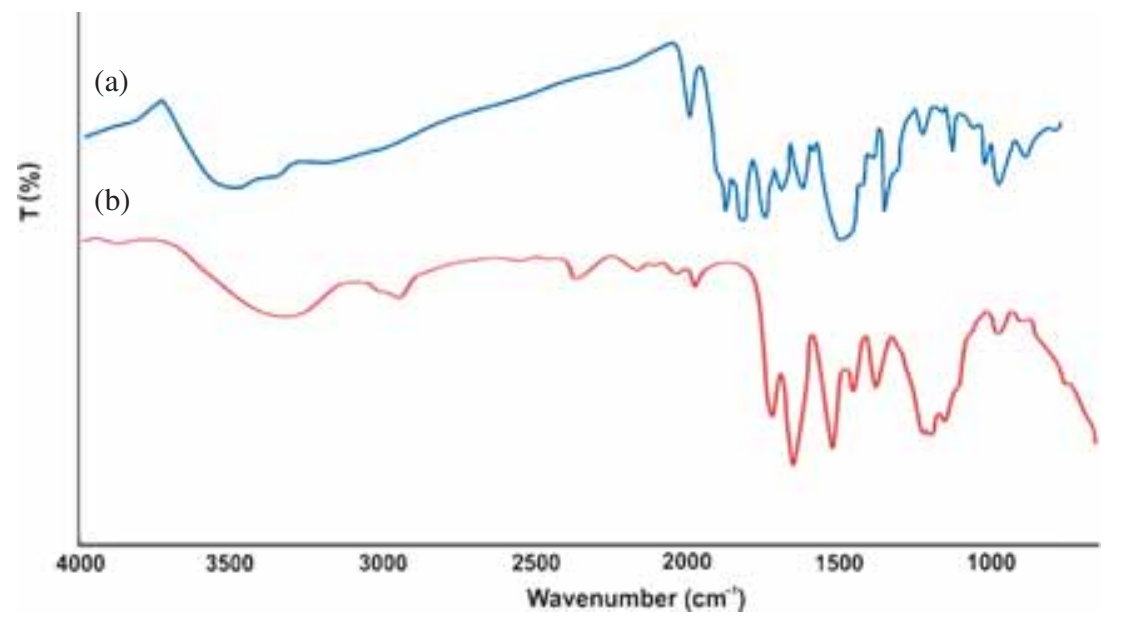

Figure 3. FTIR spectrum for the (a) plain Reactive Green 19 and (b) Reactive Green 19 attached poly(AAm-MMA) cryogel. 


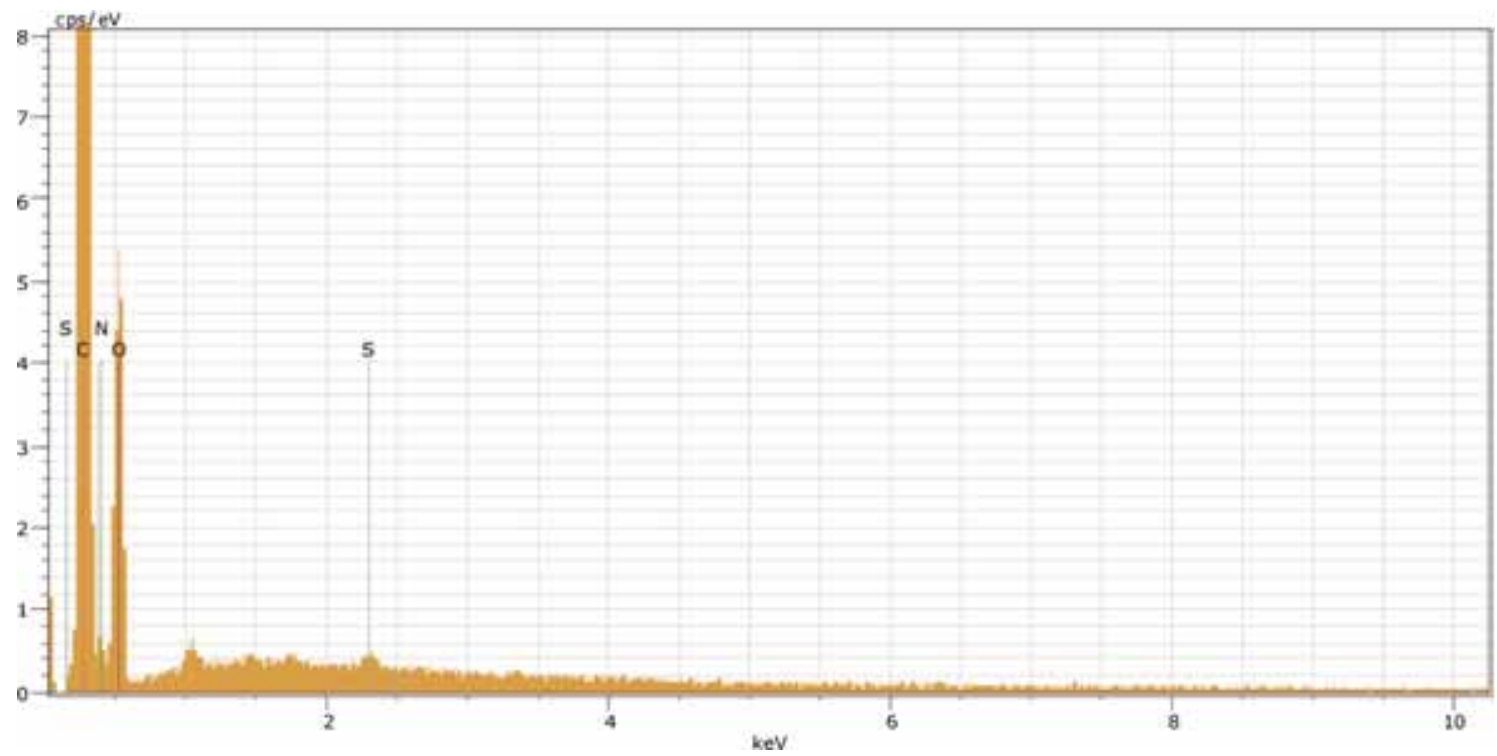

Figure 4. EDX spectrum for the Reactive Green 19 attached poly(AAm-MMA) cryogel.

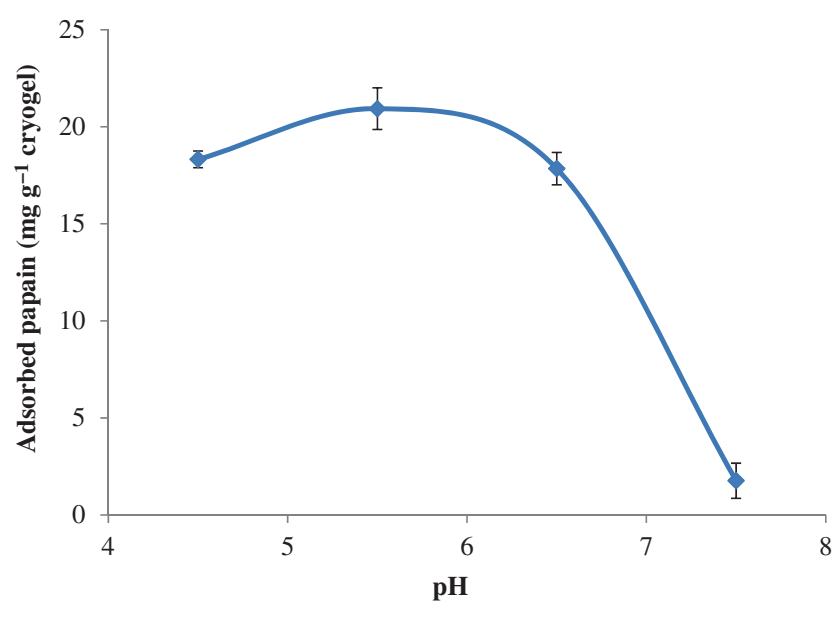

Figure 5. Effect of $\mathrm{pH}$ on the adsorption of papain onto the Reactive Green 19 attached poly(AAm-MMA) cryogel. Initial papain concentration: $0.5 \mathrm{mg} \mathrm{ml}^{-1}$; temperature: $25^{\circ} \mathrm{C}$; incubation time: $2 \mathrm{~h}$.

Figure 7 shows the effect of medium temperature on the adsorption of papain onto dye-attached cryogel. As clearly seen in this figure, temperature did not affect considerably the adsorbed amount of papain at relatively low temperatures. Adsorbed papain amount increased slowly, when temperature increased from 4 to $25^{\circ} \mathrm{C}$. On the contrary, papain adsorption efficiency of the dye-attached cryogel decreased significantly at higher temperatures. At high temperatures, proteins tend to lose their native conformations and their three-dimensional structures. Therefore, not only the enzymatic activity is affected, but also their affinity to their substrates and ligands also decreases. The reason for this decrease might be probably due to the three-dimensional distribution of the papain structure at high temperatures by affecting their affinity towards to their dye ligand.

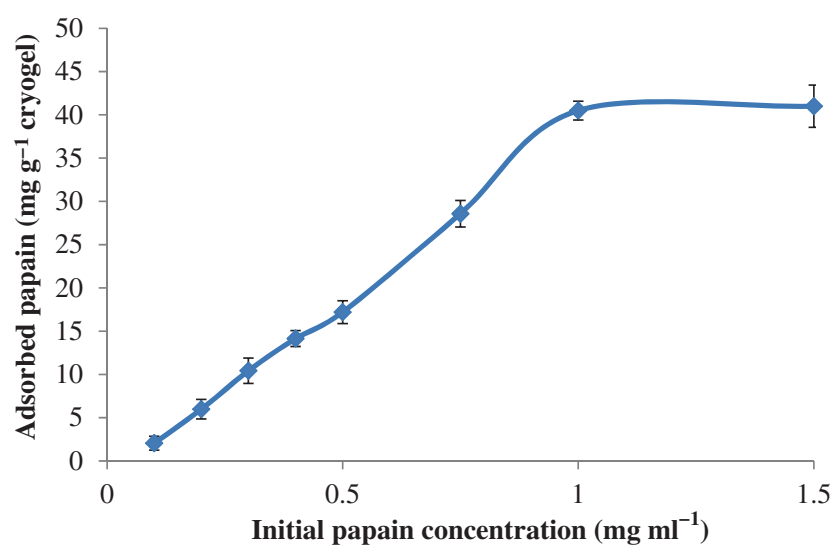

Figure 6. Effect of initial papain concentration on the adsorption of papain onto the Reactive Green 19 attached poly(AAm-MMA) cryogel. $\mathrm{pH}$ : 5.5 ; temperature: $25^{\circ} \mathrm{C}$; incubation time: $2 \mathrm{~h}$.

Table 1. Kinetic constants of Langmuir vs. Freundlich isotherms.

\begin{tabular}{lccccccc}
\hline \multicolumn{3}{c}{ Langmuir } & & & \multicolumn{3}{c}{ Freundlich } \\
\cline { 1 - 3 } \cline { 5 - 7 }$q_{\max }\left(\mathrm{mg} \mathrm{g}^{-1}\right)$ & $b\left(\mathrm{ml} \mathrm{mg}^{-1}\right)$ & $R^{2}$ & & $K_{\mathrm{f}}\left(\mathrm{mg} \mathrm{ml}^{-1}\right)$ & $1 / n$ & $R^{2}$ \\
\hline 62.11 & 3.426 & 0.9941 & 60.34 & 0.544 & 0.7364 \\
\hline
\end{tabular}

The effect of the medium ionic strength on the papain adsorption onto dye-attached cryogel is demonstrated in figure 8. As seen here, adsorbed amount of papain decreased with increasing ionic strength. $\mathrm{Na}^{+}$and $\mathrm{Cl}^{-}$ions at solution might affect the protein adsorption efficiency by disrupting electrostatic interactions between dye ligand and papain molecules. Also, $\mathrm{Na}^{+}$ions might obscure the van der Waals and hydrogen bonding interactions, by neutralizing the sulphonic acid groups of the dye molecule. 


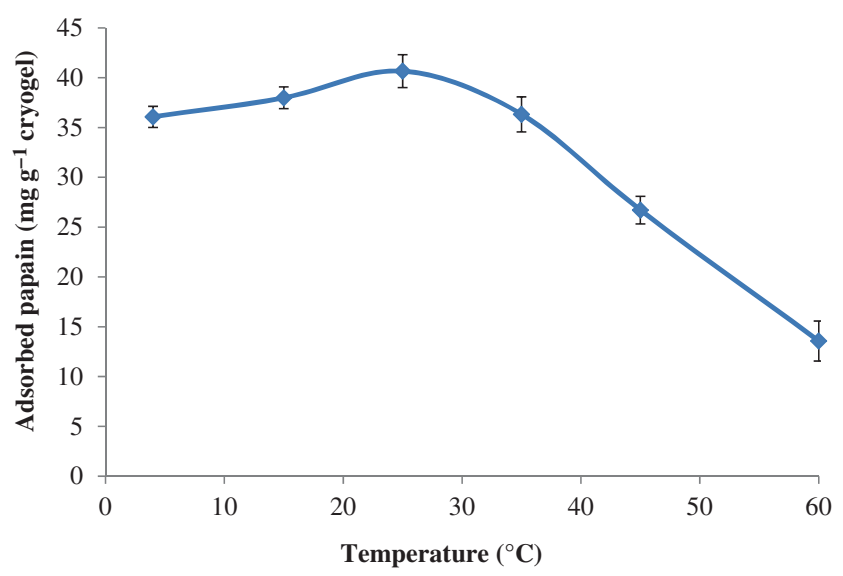

Figure 7. Effect of temperature on the adsorption of papain onto the Reactive Green 19 attached poly(AAm-MMA) cryogel. Initial papain concentration: $0.5 \mathrm{mg} \mathrm{ml}^{-1}$; $\mathrm{pH}$ : 5.5 ; incubation time: $2 \mathrm{~h}$.

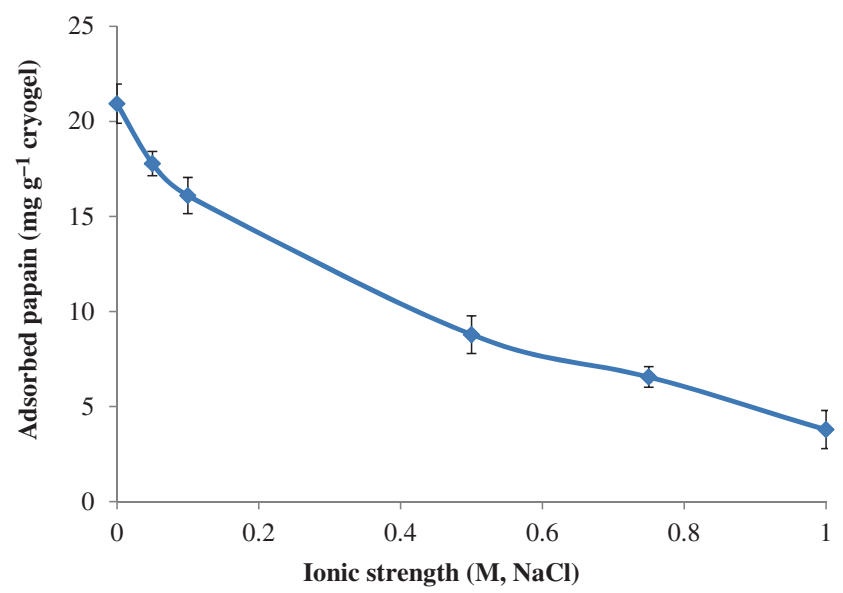

Figure 8. Effect of ionic strength on the adsorption of papain onto the Reactive Green 19 attached poly(AAm-MMA) cryogel. Initial papain concentration: $0.5 \mathrm{mg} \mathrm{ml}^{-1}$; $\mathrm{pH}$ : 5.5 ; temperature: $25^{\circ} \mathrm{C}$; incubation time: $2 \mathrm{~h}$.

\subsection{Reusability profile of the cryogel}

Repeated usability is an important feature for the industrial applicability of the synthesized polymeric adsorption material. For this, first, the adsorbed papain was desorbed from the dye-attached cryogel by using $2 \mathrm{M}$ of $\mathrm{NaCl}$ (in $\mathrm{pH} 4$ acetate buffer). Desorption yield was found to be $98.82 \%$. Discharged cryogel was further cleaned by washing with water and then equilibrated with $\mathrm{pH} 5.5$ acetate buffer solution. These cryogels were then used for the next papain adsorption steps. To investigate the reusability profile of the Reactive Green 19 attached poly(AAm-MMA) cryogel, adsorption/ desorption cycle was repeated for 10 times by using the same cryogel. At the end of the 10th cycle, adsorption capacity of the dye-attached cryogel decreased only about $2.13 \%$ (figure 9). By this finding, it can be concluded that this dye-attached cryogels can be used repeatedly without any significant decrease in their papain adsorption capacity.

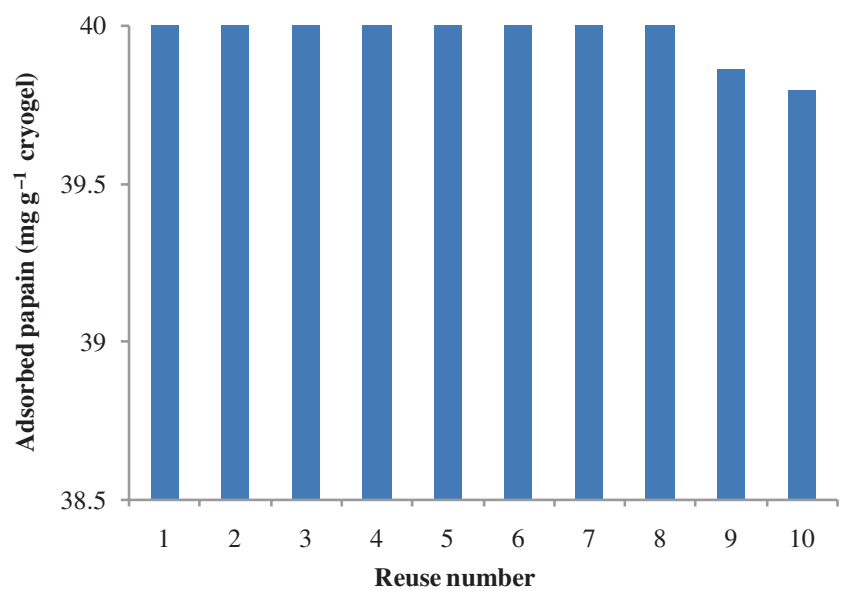

Figure 9. Reusability profile of poly(AAm-MMA) cryogel for papain adsorption.

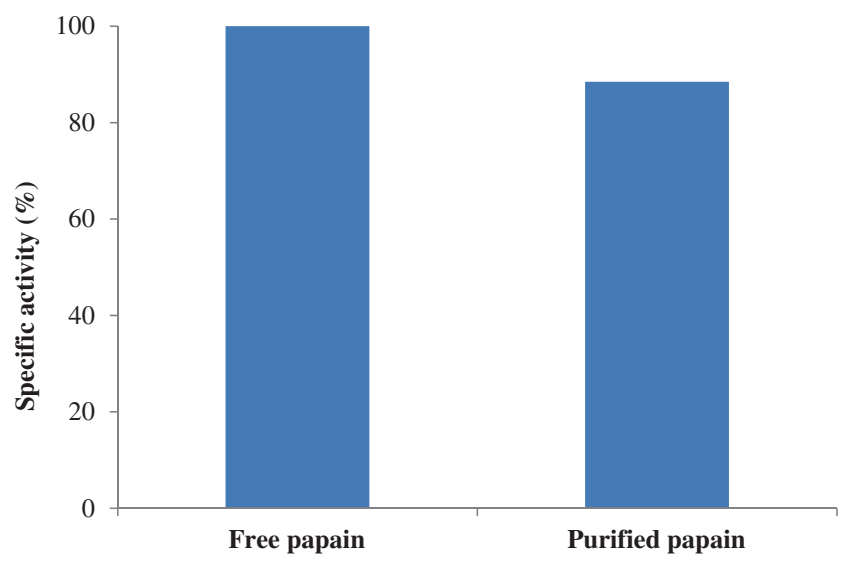

Figure 10. Activity results for free and purified papain after desorption from dye-attached cryogel column.

\subsection{Papain activity study}

There is a necessity in separation or purification studies as the final enzyme preparation must be active. In this work, activity of the desorbed papain was investigated and compared with the initial enzyme preparation. For this, papain was adsorbed onto the Reactive Green 19 attached poly(AAm-MMA) cryogel with the optimized condition, then desorbed by using desorption agent and activity of the desorbed preparation was investigated. At the end of the activity studies it was found that desorbed papain showed $88.5 \%$ of its initial specific activity (figure 10). In the light of this study, it can be concluded that desorbed papain can be used for the preparative, industrial or biotechnological applications.

\section{Conclusion}

Cryogels have been recently used intensively in various biotechnological studies such as bioseparation of biomolecules, 
immobilization of proteins and cells and three-dimensional support materials for cell culture. Their unique properties have made them a good alternative for conventional chromatographic techniques. They can be synthesized easily by using polymerizable monomers and can be derivatized with various ligands. In this work, synthesized cryogels were functionalized with dye molecule Reactive Green 19. Dye ligands have been used as an artificial ligand for biomolecules and they have still taken great interest in bioseparation areas. Synthesized dye-attached cryogels were used for the affinity adsorption of papain from its aqueous solution. System parameters for papain adsorption were optimized and reusability feature of the cryogel studied. Enzymatic activity of the papain in desorption medium was also investigated. In the light of the results of this study, it can be concluded that these newly synthesized Reactive Green 19 attached cryogels can be used for affinity adsorption of papain which have diverse industrial importance.

\section{Acknowledgement}

This work was supported by Adnan Menderes University Research Fund, by the project number FEF-10009.

\section{References}

[1] Sumantha A, Larroche C and Pandey A 2006 Food Techol. Biochem. 44211

[2] Uygun D A, Akduman B, Uygun M, Akgöl S and Denizli A 2012 Appl. Biochem. Biotechnol. 176552

[3] Pendzhiev A M 2002 Pharm. Chem. J. 36315

[4] Vasconcellos F C, Goulart G A S and Beppu M M 2011 Powder Technol. 20565

[5] Homaei A A, Sajedi R H, Sariri R, Seyfzadeh S and Stevanato R 2010 Amino Acids 38937

[6] Chen T X, Nie H L, Li S B, White C B, Su S N and Zhu L M 2009 Colloids Surf. B $\mathbf{7 2} 25$

[7] Kimmel J R and Smith E L 1954 J. Biol. Chem. 207515

[8] Finkle B J and Smith E L 1958 J. Biol. Chem. 230669

[9] Baines B S and Brocklehurst K 1979 Biochem. J. 177541

[10] Nitsawang S, Hatti-Kaul R and Kanasawud P 2006 Enzyme Microb. Technol. 391103

[11] Tombaccini D, Mocali A, Weber E and Paoletti F 2001 Anal. Biochem. 289231

[12] Govrin E and Levine A 1999 Protein Expr. Purif. 15247

[13] Nie H L, Chen T X and Zhu L M 2007 Sep. Purif. Technol. 57121
[14] Porath J, Carlsson J, Olsson I and Belfrage G 1975 Nature 258598

[15] Şenel Ş, Kassab A, Arıca M Y, Say R and Denizli A 2002 Colloids Surf. B 24265

[16] Garipcan B, Bereli N, Patır S, Arıca Y and Denizli A 2001 Macromol. Biosci. 1332

[17] Chaga G S J 2001 Biochem. Biophys. Methods 49313

[18] Gaberc-Porekar V and Menart V 2001 J. Biochem. Biophys. Methods 49335

[19] Özkara S, Yavuz H, Patır S, Arıca M Y and Denizli A 2002 Sep. Sci. Technol. 37717

[20] Garipcan B and Denizli A 2002 Macromol. Biosci. 2135

[21] Denizli A and Pişkin E 2001 J. Biochem. Biophys. Methods 49391

[22] Nash D C and Chase H A 1997 J. Chromatogr. A 77655

[23] Boyer P M and Hsu J T 1992 Chem. Eng. Sci. 47241

[24] Zeng X and Ruckenstein E 1996 J. Membr. Sci. 117271

[25] Uygun M, Uygun D A, Altunbaş C, Akgöl S and Denizli A 2014 Sep. Sci. Technol. 491270

[26] Başar N, Uzun L, Güner A and Denizli A 2007 Int. J. Biol. Macromol. 41234

[27] Wongchuphan R, Tey B T, Tan W S, Taip F S, Kamal S M M and Ling T C 2009 Biochem. Eng. J. 45232

[28] Yılmaz M, Bayramoğlu G and Arıca M Y 2005 Food Chem. 8911

[29] Kaya N, Uygun D A, Akgöl S and Denzli A 2013 Appl. Biochem. Biotechnol. 1692153

[30] Uygun M, Akduman B, Uygun D A, Akgöl S and Denizli A 2015 J. Biomater. Sci. 26277

[31] Yavuz H, Akgöl S, Say R and Denizli A 2006 Int. J. Biol. Macromol. 39303

[32] Plieva F M, Galaev I Y and Mattiasson B J 2007 Sep. Sci. 30 1657

[33] Lozinsky V I, Plieva F M, Galaev I Y and Mattiasson B 2012 Bioseparation 10163

[34] Arpa Ç, Bereli N, Özdil E, Bektaş S and Denizli A $2010 \mathrm{~J}$. Appl. Polym. Sci. 1182208

[35] Homaei A, Barkheh H, Sariri R and Stevanato R 2014 Amino Acids 461649

[36] Kembhavi A A, Kulkarni A and Pant A 1993 Appl. Biochem. Biotechnol. 3883

[37] Bradford M M 1976 Anal. Biochem. 72248

[38] Martins M C L, Naeemi E, Ratner B D and Barbosa M A 2003 J. Mater. Sci. Mater. Med. 14945

[39] Uygun M, Akduman B, Akgöl S and Denizli A 2013 Appl. Biochem. Biotechnol. 1701815 